$\mathbf{T}_{\mathrm{b}}^{\mathrm{h}}$ he University of Houston's (UH) student body is one of the most diverse in the nation, and first-year writing courses are where the UH Libraries Instruction Team teach students early in their academic careers. ${ }^{1}$

These students bring a wealth of lived experience to the classroom that our team sought to include in a lesson on critically evaluating information. We developed everyday information-seeking scenarios to discuss the contextual nature of information use and the concept of information appropriateness and fit. By drawing on the Authority is Constructed and Contextual, Information Creation as a Process, and Searching as Strategic Exploration frames, students used their personal experiences to make their own critical evaluative processes explicit as a way to demystify the evaluation of information in an academic context.

In this article, we will share our development process, details about our lesson plan, sample scenarios, and connections between this activity and the ACRL Framework for Information Literacy for Higher Education.

The Instruction Team, situated within the Liaison Services Department at UH Libraries, is responsible for the integration of information literacy (IL) in certain foundational undergraduate courses, including the two-course sequence of first-year writing (FYW). Historically, the Instruction Team and the FYW program have had a strong partnership, with members of the team teaching assignmentfocused IL classes and training first-year writing instructors on the integration of IL in writing instruction. IL instruction in FYW focuses on analyzing visual media, ethical incorporation of sources, research question or topic development, strategic searching, and the critical evaluation of information. All of these concepts supplement and shape the development of students as writers and information creators.

\section{Lesson development}

In 2019, after the arrival of a new coordinator and two new team members, the Instruction Team began to evaluate the existing lesson plans for FYW. At the time, information evaluation in FYW was taught as more of a checklist, where students brainstormed evaluative criteria and then used the criteria to evaluate an article. However, this approach felt like an oversimplification of the complex process of information evaluation. In our attempt to move away from evaluation as a checklist, we went through several iterations of the information evaluation lesson.

We experimented with using the rhetorical triangle (author, audience, purpose) as a way to teach students about source evaluation. However, it was difficult to get past surfacelevel explanations with this method in the

Veronica Arellano Douglas is instruction coordinator, email:vadouglas@uh.edu,Emily Deal is English librarian, email: endeal@uh.edu, and Carolina Hernandez is instruction librarian, email: chernandez61@uh.edu, at the University of Houston

๑ 2021 Veronica Arellano Douglas, Emily Deal, and Carolina Hernandez 
short time allotted for library instruction sessions. We tried to adopt Kevin Seeber's process cards activity to highlight the connection between the form of information sources to their function and use, which was helpful, but didn't address the importance of determining which sources were most appropriate for a given situation. ${ }^{2}$

We did not realize it at the time, but in our attempts to develop an information evaluation lesson plan that resonated with our students, we were enacting the same kind of iterative process that we encourage our students to lean into during their research. Try something new, reflect, and revise. Our team repeated this process several times in class sessions and in an intensive team brainstorming session and ultimately concluded that we needed to address just two of the many facets of information evaluation: appropriateness and fit. In focusing on appropriateness and fit, we wanted students to consider the usefulness of an information source to their information need as well as its authoritative appropriateness to their situational context.

Given the complexity and nuance that accompanies the act of evaluating information, we knew we wanted to take a problem-based approach-"using real-world problems ... as the vehicle to promote student learning of concepts and principles" - in our learning activity. ${ }^{3}$ Where perhaps we differed from other IL learning activities in our application of problem-based learning is that we were less concerned with answers or solutions and more focused on uncovering the thoughtprocesses by which students make evaluative judgements of information.

\section{Why scenarios?}

Developing an activity built on potential real-life information-seeking scenarios was an ideal way for us to dig into the metacognition (or thinking about the thought process) of information evaluation. ${ }^{4}$ As previously stated, students at UH have a wealth of life experience that they bring to the classroom, which informs the way they approach and solve information problems. Rather than impose a predetermined, academic set of evaluation criteria (or steer students in that direction), we wanted students to share their own methods of seeking out information and determining which sources to use to solve a problem. We had no "right" answer we were angling towards in our scenarios. Instead, we wanted students to see their own strengths and abilities in making sound judgments about what information to trust in their own lives based on their own experiences. ${ }^{5}$

We created a total of ten real-life information-seeking scenarios that we tried to relate to the everyday experiences of students living, working, and studying in the Houston metro area. ${ }^{6}$ Scenarios included everything from finding the best route to and parking at the Houston Rodeo to picking a fantasy football team to determining the best eyeliner to purchase. We chose to develop these types of scenarios rather than academic ones to demystify the process of information evaluation and highlight the critical thinking skills that are constantly used in our day-to-day lives. There is something jarring for early-career students about suddenly having to decide what's appropriate for an academic paper that makes all of their previous critically evaluative experience seem unimportant. This could be because of the way we tend to divorce academic thinking from lived experience (as though one doesn't inform the other) or because of the unfamiliar nature of academic research in a college or university setting. We wanted to remove the pressure to determine whether a source was "good enough" for an academic paper and instead focus on what makes information worthwhile, useful, and trustworthy in a more familiar situation. Doing so gives students the opportunity to delve into the practice of critical information evaluation without having to worry about being academically correct.

One of our favorites was the following:

\section{You're sick!}

You've had a weird pain in your foot for the last few days that makes it difficult to walk. You don't have time to go to the doctor this 
week, so you decide to do some research into what could be wrong. How do you find out:

- What could be causing this pain?

- What foot disorders exist?

- Am I dying?

- How can I treat or lessen the pain?

As with all our scenarios, this one was open-ended and broken down into discrete questions. Our goal in proposing these situations was not to lead students towards predetermined answers, but to uncover how they would seek out answers and why they would use particular information sources.

In addition to scenario-specific questions, we developed shared metacognitive questions that would be applied to all scenarios:

1. How did you decide where you might look for that information?

2. Is there a reason to trust one source over another?

3. Would you look at more than one source for an answer? Why or why not?

By asking these questions, we wanted to make explicit the implicit judgements students make in information-seeking situations and tie those evaluative processes to broader concepts within the Framework for Information Literacy. Addressing trust is tied to the notion of authority and credibility, which, as the Authority is Constructed and Contextual frame states, can vary based on need and community. In determining where to look for information and whether to consult multiple sources, students are thinking through the concept of Searching as Strategic Exploration. They are also determining the scope of their need and whether they need to keep looking or are satisfied with the information they find.

The notion of Information Creation as a Process comes into play as students evaluate the information they might use to answer a question based on why and how it was created. This line of questioning is a way of relating the Framework to IL in a broader context, or, as one first-year writing instructor put it, "This shows me that when the outcome really matters to students-when they have to live with the consequences of a decision or spend money-they put a lot of thought into the information they consult to make a decision."

\section{In the classroom}

In this lesson, students self-select into small groups of three to five, and each group selects between two different scenarios. After they have selected their scenario, talked through the discussion questions, and recorded responses, the whole class reconvenes. Each group shares their responses and thought processes, and the librarian facilitates a whole-class discussion based on their replies.

As with any lesson plan, there is always the possibility that a class will not shake out quite as you expected. But again, we created this lesson with the intention of letting our students' experiences guide the discussion and learning process. Not surprisingly, students' responses to the initial hypothetical information-seeking questions and the metacognitive questions revealed a sophisticated and nuanced understanding of the nature of authority and credibility, why certain information is created, and how it is best used. They have good instincts and understand what they need to do when evaluating sources for their particular needs.

Although responses vary from class to class, many students consistently mention the need to determine whether information is relevant to their needs, express how they determine expertise, and consider whether the information they use offers a variety of perspectives.

For example, in the "You're Sick!" scenario, students will often (shyly) mention their mother as a credible source they might turn to for health information. Digging into this response reveals the contextual nature of expertise. Students explain that their mother has prior experience taking care of them, 
so they see them as experts in this type of situation. This type of response allows us to talk about "Authority is Constructed and Contextual," which they already seem to understand, but talking through it helps make this thought process explicit.

In another scenario, where they are trying to pick a new restaurant to try, students talk about needing to look at a variety of reviews, pointing out that one customer's bad experience is not always indicative of a restaurant's quality. This demonstrates an understanding of the importance of gathering multiple perspectives.

Drawing out the underlying concepts in their evaluative process of everyday information scenarios gives students the opportunity to apply them in an academic context. After the everyday scenario activity, each group receives a research question that is an academic variation on their original scenario. ${ }^{7}$

For the group working on the "You're Sick!" scenario, the academic version focuses on working on a health paper about bunions and foot pain, which requires finding information about the causes and treatment of bunions. They go through a similar process of determining what kind of information will best fit their need, and what makes it appropriate for academic research.

\section{Conclusion}

The day-to-day scenarios activity has provided a way for our students to build on their prior knowledge by having them reflect on their process of evaluating information in a familiar context. Though we initially developed this activity for face-toface classes, the COVID-19 pandemic gave us the opportunity to adapt it for an online learning experience, ultimately becoming the core of our asynchronous Evaluating Information Sources module. ${ }^{8}$

This strengths-based approach to teaching components of the Framework demonstrates how our students are already knowledgeable and savvy when it comes to IL in their everyday lives.
We look forward to finding ways to similarly emphasize our students' lived experiences throughout our teaching. We urge other instruction librarians to assume the best of their students' critical thinking abilities, help them build on their existing strengths, and find ways to relate students' experiences to the Framework for Information Literacy for Higher Education.

\section{Notes}

1. "Campus Ethnic Diversity," U.S. News \& World Report, accessed June 10, 2021, https://www.usnews.com/best-colleges/rankings /national-universities/campus-ethnic-diversity.

2. Kevin Patrick Seeber, "Teaching 'Format as a Process' in an Era of Web-Scale Discovery," Reference Services Review 4, no. 1 (January 1, 2015): 19-0, https://doi.org/10.1108/RSR-07 -2014-0023.

3. "Problem-Based Learning (PBL)," Center for Innovation in Teaching \& Learning, accessed June 10, 2021, https://citl.illinois.edu/citl-101 /teaching-learning/resources/teaching-strategies /problem-based-learning-(pbl).

4. Nancy Chick, "Metacognition," Vanderbilt University Center for Teaching, accessed June 10, 2021, https://cft.vanderbilt.edu/guides-sub-pages /metacognition/.

5. Chelsea Heinbach, Brittany Paloma Fieldler, Rosan Mitola, and Emily Pattni, "Dismantling Deficit Thinking: A Strengths-Based Inquiry into the Experiences of Transfer Students in and out of Academic Libraries," In the Library with the Lead Pipe, February 6, 2019, http://www.inthelibrarywiththeleadpipe. org/2019/dismantling-deficit-thinking/.

6. See the following Google Doc for a complete list of everyday life activity scenarios at https://docs.google.com/document/ d/1RrcgTLzFBviluYPKzr6OsfYsrNf3_ROnISXC IZw057M/edit?usp=sharing.

7. See the following Google Doc for a complete list of academic scenarios: https:// docs.google.com/document/d/1FPMRmSV1X o9lMZikV7vIxqLW4fxcGnU8i4CoAPVaqmk /edit?usp=sharing.

8. See Evaluating Information Sources online lesson at https://rise.articulate.com/share/ G2yMtSMhC3EHbyBohwbrYfiLIqRXXbcu. „2 